\title{
Construction of a Bayesian Network for the Assessment of Agri-Environmental Measures - The Case Study of the Venice Lagoon Watershed
}

\author{
Marta Carpani ${ }^{*}$, Carlo Giupponi ${ }^{2}$ \\ ${ }^{1}$ Agrosystèmes et développement territorial (UMR 1284 AGIR), Istitut National de la Recherce Agronomique \\ Toulouse, Chemin de Borde Rouge BP 5262731326 Castanet Tolosan, France \\ ${ }^{2}$ Center for Environmental Economics and Management, Dipartimento di Scienze Economiche, Università \\ "Ca' Foscari" di Venezia, San Giobbe 873, 30121 Venezia, Italia
}

Received: 14 September 2009. Accepted: 10 January 2010.

\begin{abstract}
A methodological framework was designed to assess the effectiveness of agri-environmental policy measures adopted by the Veneto Region to reduce diffuse water pollution of agricultural origin. Two already existing methodologies were combined in a new flexible approach for policy assessment: Conceptual Modelling and Bayesian Networks (BNs). The former supported the development of a shared conceptual model (a cognitive map) of the agro-ecosystem of the study area; while the latter allowed the development of a probabilistic model coherent with the cognitive map. BNs were selected because they allow analyses with scarce data; they can be updated when further information becomes available, and are easily understandable by layperson. The paper reports the results obtained in the Venice Lagoon Watershed (VLW) case study, where the current agri-environmental measures were assessed in order to identify their effectiveness in terms of reduction of nitrogen releases in water bodies connected to the lagoon ecosystem. Preliminary results obtained by implementing expert opinions in the BN pointed out the likely limited effects of the measures on the declared objective of safeguarding the lagoon ecosystem. Final remarks are drawn about the potentials of the proposed methodology.
\end{abstract}

Key-words: cognitive map, Bayesian Network, policy assessment framework, agri-environmental measures.

\section{Introduction}

As widely known two main sources of pollution that threaten water quality are point or nonpoint sources. Point sources imply the identification of discrete pollution sources, plainly detectable, while non-point sources are not clearly identifiable. This work deals with diffuse pollution (or non-point source pollution as defined by the EEA Glossary ${ }^{1}$ ), a source that is strongly dependent on land use, with agriculture being commonly considered as the main cause of this pollution, and agrochemicals recognised as the main causes of water depletion (Ripa et al., 2006).

Agricultural policy recognises environmental impacts caused by agriculture. For this reason different policy mechanisms have been adopted in order to redress agri-environmental problems, and to reduce imbalances between agricultural policies and environmental objectives. Among these mechanisms there is the agri-environmental measures definition.

Different analysis scales are involved in dealing with diffuse pollution of agricultural origin. In general analysis, measures definition and adoption need to be tailored to the appropriate temporal and spatial scale because different spatial and temporal scale considerations lead to different results, dealing with different analysis perspective.

\footnotetext{
* Corresponding Author: Tel.: +33 (0)5 6128 5744; Fax: +33 (0)5 6173 5537. E-mail address: marta.carpani@toulouse. inra.fr.

${ }^{1}$ http://glossary.eea.europa.eu/EEAGlossary/N/non-point_sources
} 
The hierarchical spatial level presented in this work is the watershed scale analysed through a stochastic simulation model for the assessment of agri-environmental measures' effectiveness.

The proposed analysis framework performs an ex-post evaluation of the policy measures applied in the case study of the Venice Lagoon Watershed (VLW), with the aim of contributing to the assessment of the effectiveness of investments, and to the planning of new strategies for the local implementation of the Water Framework Directive (WFD, 2000/60/EEC).

Handling water management issues and the assessment of policy measures highlight the need for developing a participatory approach. In participatory processes it is necessary to analyse complex problems considering different knowledge disciplines (environmental, economic, social, etc.). These disciplines frequently suffer of lack of communication among them and often have opposite necessities. Moreover, the participatory process must be transparent in communication among scientist and policy-makers and towards the broader public, thus contributing significantly to an improvement in the quality of the results of decision processes and their potential for practical implementation and overcoming of conflicts between the various stakeholders.

The analysis framework presented in this paper is also devised for application in participatory processes aimed at ex-ante evaluation of policy measures, thanks to its capability to communicate and share the available information in a transparent manner, even if data are scarce or have high uncertainty, which the typical case during the development of new policy tools. Moreover, this framework allows knowledge updating: when new information become available they are easily integrated to update systems' knowledge.

The new methodology developed was tested using the VLW case study to assess the agri-environmental measures effectiveness. For the test it was decided to use a fully functional model filled with a priori distribution for each system's variable entirely obtained with a formal elicitation of experts' judgements (i.e. through an ad hoc elicitation protocol). The use of experts' judgment data was chosen to test the future framework applications in ex-ante evaluations, generally characterised by scarce information available.

\section{Materials and methods}

The methodological framework set up for the VLW case study follows the scheme depicted in Figure 1, with the first phase of conceptual modelling already published in Giupponi et al. (2008) and the subsequent phases of building and execution of the Bayesian Network presented in this paper.

The first phase, carried out in a previous participatory modelling workshop, produced a cognitive map, a conceptual model of pollution phenomena coherent with the DPSIR framework (EEA, 1999). A semi-structured procedure developed by Nadkarni and Shenoy (2004) was applied to transform the cognitive map into the BN structure (see Fig. 1 - BN structure definition box). This structure was filled with conditional probabilities elicited from experts by means of a structured protocol. Through an ad hoc questionnaire and a face-to-face interview, the involved experts compiled prior conditional probability tables (CPTs) for each node of the BN. Equal-weighted average aggregation of multiple experts prior probabilities (Clemen and Winkler, 1999), was followed by an in depth uncertainty analysis to assess the effects of experts' subjectivity on the outputs (see Fig. 1 $\mathrm{BN}$ model box). The result is a fully functional

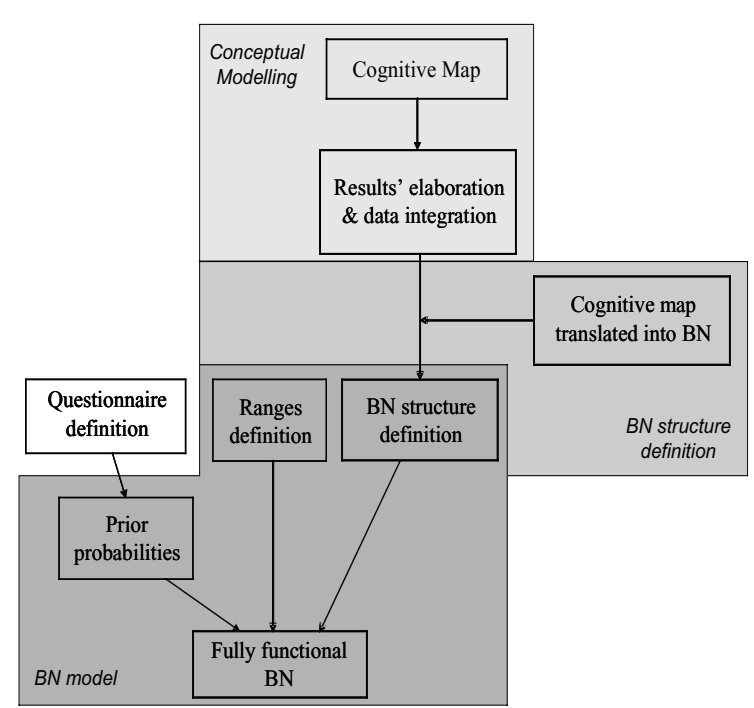

Figure 1. Framework built for the application of the innovative approach. 
BN allowing policy assessment through the integration of information about the policy measures and the environment: financial resources and farmers' applications (management area of the $\mathrm{BN}$ ); agricultural and hydrological variables (agro-environmental area). Subsequently the $\mathrm{BN}$ was updated including the evidences acquired in a parallel project, achieved by applying a hydrological mechanistic model (GLEAMS, Leonard et al., 1987).

\section{Methods}

The real world is perceived through mental models that could vary from one person to another. These mental models are utilised to gather complex problems with the aim of to interpret, frame, simplify, and make sense of them (Lasut, 2005). A cognitive map (or causal map) is a graphical representation of a mental model where concepts are linked each other through adequate graphical symbols. Cognitive maps facilitate the elicitation process and can be used to summarise, communicate, and inform the public about a particular problem therefore are very useful in participatory modelling.
The elements and cause-effect links that characterise the analysed system were elicited through a structured approach that in the VLW case study imply an open discussion among experts. Subsequently their judgments were organised in a cognitive map based on the DPSIR approach (Driving forces, Pressures, States, Impacts, Responses - EEA, 1999). The obtained cognitive map (Gipponi et al., 2008), focuses on cause-effect links among agricultural and breeding activities (grouped as drivers and pressures), environmental impacts (grouped as impacts) and agri-environmental measures (grouped as responses). The aim of the workshop was to collect information related to the environmental meaning and mechanisms of some measures, and to define a shared scheme to frame experimental evidences and monitoring data (Fig. 2).

Bayesian networks (BNs) are models which operate through the combination of conditional probability tables (CPTs). Their acyclic graphical structure is composed by nodes, state of nodes, and links. The graphical part illustrates and communicates the causal structure of the

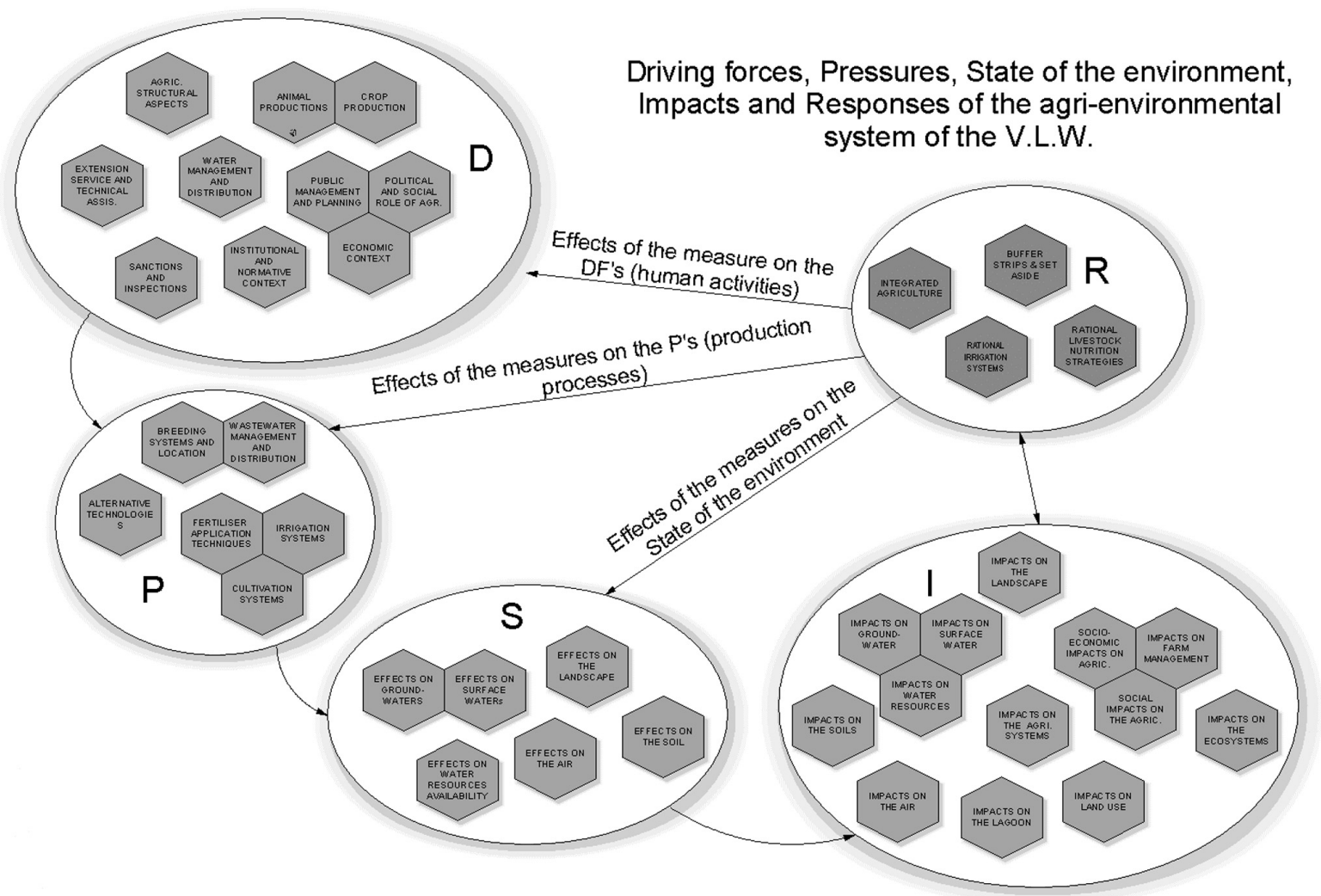

Figure 2. Cognitive map obtained for the VLW case study organised as a DPSIR (Driving forces, Pressures, States, Impacts and Responses) scheme (Giupponi et al., 2008). 
model and the interactions (the links of the network) among the system variables (the nodes of the network, each one defined by different states combined with their probabilities). The strength of the connections between variables is quantified by the CPTs that underline each node. One great potential of the BN instrument lies in its dual structure (graphical and probabilistic) which facilitates reasoning under uncertainty in participatory contexts, typical of problem exploration contexts, characterised by limited availability of quantitative data.

Each node of the BN represent a system variable and has a finite set of mutually exclusive (i.e. that variable must take one value at a time) and exhaustive states. The states or conditions of the variables can be categorical, continuous or discrete. Two nodes related by a link indicate that one variable affects or causes the other and an arc indicates the direction of this influence.

The conditional probabilities specify the belief that a node will be in a particular state given the states of those nodes which affect it directly (parent nodes). These sets are represented by CPTs, one per each node, and express how the relationships between the nodes operate. The CPTs contain entries for every possible combination of the states of the parent nodes. Their complexity, therefore, increases exponentially as the number of parent nodes increase and also with the increase of the number of ranges settled to define each node.

The probability representing our knowledge of the subject a priori is called "prior", and indicates the probability that an input parameter will be in a particular state. When new data or information become available, the prior probabilities are updated through the iterative application of the Bayes' Theorem (Equation 1).

The Bayes' theorem states that the probability of a hypothesis $\mathrm{F}$ is conditioned upon some evidence E:

$$
\mathrm{P}(\mathrm{F} \mid \mathrm{E})=\frac{P(E \mid F) P(F)}{P(E)}
$$

where the posterior probability of an event $\mathrm{F}$, $\mathrm{P}(\mathrm{F} \mid \mathrm{E})$, is obtained by multiplying the prior probability of event $\mathrm{F}, \mathrm{P}(\mathrm{F})$, with its likelihood $\mathrm{P}(\mathrm{E} \mid \mathrm{F})$ normalized dividing by $\mathrm{P}(\mathrm{E})$ (Korb and Nicholson, 2004; O'Hagan at al., 2006). In this way the available evidence is incorporated into a posterior probability. The new outcome represents the probability that a variable will be in a particular state, given the input evidence, the conditional probabilities, and the rules governing how the probabilities combine.

Cognitive maps can play an important role in the design of BNs, but there are meaningful differences between causal maps and BNs, that do not allow to directly use the former as a structure of the latter.

The main difference between causal maps and BNs is the meaning of arcs and their absence. BNs can be defined as I-maps, in which missing arcs imply conditional independence assumptions, but the presences do not necessarily imply causality. Causal maps, in comparison can be defined as D-maps, where an arrow implies a relationship between variables, but the lack of an arrow does not imply independence between variables. Another important characteristic of $\mathrm{BNs}$ is that they are acyclic graphs; therefore causal loops (e.g. feedbacks) that could be present in causal maps should be avoided.

In order to transform the structure of an acyclic causal map in a $\mathrm{BN}$, it is necessary to apply a systematic procedure to construct a ' $\mathrm{BN}$ causal map', which is both D-map and I-map that avoids loops (i.e. a 'perfect map', according to Korb and Nicholson, 2004). The 'causal BN' structure created through this methodology is a robust structure based on causality and conditional independence, which is extremely useful when cause-effect relationships are significant (Nadkarni and Shenoy, 2004).

\section{Case study}

The semi-formal process proposed by Nadkarni and Shenoy (2004) transforms the cognitive map (i.e. a D-map), presented in Figure 2 in a 'perfect map' that is the draft structure of the BN model for the VLW case study, were every link imply causality (as in a D-map) and a link absence imply conditional independence (as in a I-map). This approach was selected because it is suitable in environmental field, especially when causal maps are used to represent experts' knowledge. Nonetheless, the preliminary BN structure definition, obtained through this procedure resulted in a too complex model that encloses a high number of variables. Thus, to ob- 
tain a BN structure formed by relevant variables and meaningful links dependencies that characterise the system, a refinement procedure was applied. The objectives of the analysis guided the simplification of the first draft network, to obtain a synthetic and realistic model that accomplished the system's description and avoided nonessential variables. In the VLW case study the BN structure refinement was performed through the application of simplification techniques to obtain a clear model that could be easily understandable by the experts to be involved and thus filled with prior probabilities. The fundamental rule applied to simplify the model structure is to enclose variables and states, that could 'reach' (i.e. affect) the outcomes, thus avoiding nonessential variables or states inclusion (Borsuk et al., 2004).

Having consolidated the BN graphical and causal structure, CPTs were defined. Probability functions are in theory continuous, but their inclusion in the CPTs raises huge calculus problems, therefore many BN tools require their discretisation, as in the case of GeNIe software (http://genie.sis.pitt.edu/) selected for this work. Therefore, three states have been defined per each node (i.e. high; medium, low), with ranges defined upon empirical knowledge about the variability of the variables in the case study area (Tab. 1). Raw data from local databases (e.g. regional statistical database) and model outputs have been analysed to obtain the minimum and maximum levels that each variable could reach and intermediate levels have been defined considering for example the values corresponding to the $33^{\text {th }}$ and $67^{\text {th }}$ percentiles.

Regarding the nodes related to measure applications, the percentages that indicate a low, medium or high level of application where subdivided to focus the attention on the low part of the spectrum (from 0 to $5 \%$ and from 5 to $10 \%)$, because at the time of the elaboration the number of farms joining the agri-environmental scheme represented only $1 \%$ of the total number of farms in the VLW (around 55,000).

The prototype of the $\mathrm{BN}$ model was firstly presented for validation to a group of experts covering the various expertises related to the identified variables and subsequently compiled with their support provided though an ad hoc questionnaire. The elicitation procedure was conducted through a structured protocol de- signed on purpose to the VLW case study, in accordance with what proposed in the literature (Clemen and Reilly, 2001; Morgan and Herion, 1990).

Elicited probabilities for each variable have been used to fill-in the CPTs, with three experts filling a specific questionnaire for each area of expertise. Therefore, three different people expressed their opinion on the same subject, answering the same questions, thus collecting data that could provide insights on the real variable value as suggested by Mayer and Booker (1991) and O'Hagan et al. (2006). The probabilities provided by the expert triplets were subsequently averaged to obtain the prior probabilities inserted into the model, but also separately stored for later analysis of the uncertainty related to divergences in experts' opinions. The model structure hides a partial correlation among nodes because of the dependencies among variables. Given that it was not possible to determine the exact level of dependencies among variables that characterise the model and that subsequently influence the experts' answers, the extreme situations have been analysed: complete correlation and absence of correlation. For the complete correlation all the variables that pertain to the same areas of expertise are considered as completely correlated; the analysis was performed by the group uncertainty analysis. For the other extreme, all the variables are considered as not correlated and therefore analysed by the global uncertainty analysis. Given the uncertainty analysis results, briefly presented below, in the VLW case study the equal-weighted average value was considered suitable for use in the CPTs for parameterisation of the prior $\mathrm{BN}$.

The following example can help clarifying the procedure. The experts provide the probability of being in each state of the variable (e.g. low vs. medium vs. high). As shown in Table 2, Expert 1 distributed the $100 \%$ probability across the categories assigning $10 \%$ to the low state, $20 \%$ for the medium state, and $70 \%$ for the high state. Note that the category for each state variable of the VLW case study was defined individually as a range to clearly define the elicited quantities. Having multiple experts, the expert judgments were averaged per each category to obtain an aggregate probability dis- 
Table 1. Nodes and ranges definition.

\begin{tabular}{|c|c|c|c|c|c|c|c|}
\hline Variables & Unit of measure & Source & MIN & $33.4^{\circ}$ & $66.6^{\circ}$ & Max & Note \\
\hline $\begin{array}{l}\text { FUNDS FOR } \\
\text { IRRIGATION }\end{array}$ & Milion of euro & Veneto Region & $\begin{array}{l}\text { From } 10 \\
\text { to } 13\end{array}$ & & $\begin{array}{l}13 \\
15\end{array}$ & $\begin{array}{l}\text { More } \\
\text { then } 15\end{array}$ & \\
\hline $\begin{array}{l}\text { FUNDS FOR } \\
\text { BUFFER STRIP - } \\
\text { SET ASIDE }\end{array}$ & Milion of euro & Veneto Region & Up to 10 & & 12 & $\begin{array}{l}\text { From } 12 \\
\text { to } 15\end{array}$ & $\begin{array}{l}\text { Data from regional } \\
\text { database } \\
\text { considering all the }\end{array}$ \\
\hline $\begin{array}{l}\text { FUNDS FOR } \\
\text { INPUT } \\
\text { AGRICULTURE }\end{array}$ & Milion of euro & Veneto Region & Up to 12 & & $\begin{array}{l}12 \\
15\end{array}$ & $\begin{array}{l}\text { More } \\
\text { then } 15\end{array}$ & Funds supplied \\
\hline $\begin{array}{l}\text { FUNDS FOR } \\
\text { BREEDING }\end{array}$ & Milion of euro & Veneto Region & $\begin{array}{l}\text { From } 6 \\
\text { to } 8\end{array}$ & & & $\begin{array}{l}\text { From } 10 \\
\text { to } 16\end{array}$ & \\
\hline $\begin{array}{l}\text { IRRIGATION } \\
\text { APPLICATION }\end{array}$ & $\%$ & $\begin{array}{l}\text { AGeNDA } \\
\text { database }\end{array}$ & $0 \%$ & $5 \%$ & $10 \%$ & $100 \%$ & \\
\hline $\begin{array}{l}\text { BUFFER STRIP - } \\
\text { SET ASIDE } \\
\text { APPLICATION }\end{array}$ & $\%$ & $\begin{array}{l}\text { AGeNDA } \\
\text { database }\end{array}$ & $0 \%$ & $5 \%$ & $10 \%$ & $100 \%$ & $\begin{array}{l}\text { Percentage of the } \\
\text { total amount of } \\
\text { farms of the VLW }\end{array}$ \\
\hline $\begin{array}{l}\text { LOW INPUT } \\
\text { AGRICULTURE } \\
\text { APPLICATION }\end{array}$ & $\%$ & $\begin{array}{l}\text { AGeNDA } \\
\text { database }\end{array}$ & $0 \%$ & $5 \%$ & $10 \%$ & $100 \%$ & \\
\hline $\begin{array}{l}\text { BREEDING } \\
\text { APPLICATION }\end{array}$ & $\%$ & $\begin{array}{l}\text { AGeNDA } \\
\text { database }\end{array}$ & $0 \%$ & $5 \%$ & $10 \%$ & $100 \%$ & \\
\hline RAINFALL & $\mathrm{mm}$ & $\begin{array}{l}\text { Annual } \\
\text { average from } \\
\text { two data sources: } \\
\text { Agenda, ARPAV_08 }\end{array}$ & 690 & 800 & 910 & 1100 & $\begin{array}{l}\text { Consider data from } \\
4 \text { wheaterstation of } \\
\text { the VLW }\end{array}$ \\
\hline IRRIGATION & $\mathrm{mm}$ & $\begin{array}{l}\text { Report for } \\
\text { Veneto Region }\end{array}$ & 0 & 100 & 300 & 600 & $\begin{array}{l}\text { Values confirmed } \\
\text { by a couple of } \\
\text { experts }\end{array}$ \\
\hline LAND USE & $\mathrm{kg} \mathrm{N} / \mathrm{ha}$ & $\begin{array}{l}\text { Typical crop } \\
\text { rotations }\end{array}$ & Intensive & Tra & ional & Extensive & $\begin{array}{l}\text { See Note AGeNDA } \\
\text { database }\end{array}$ \\
\hline $\begin{array}{l}\text { MINERLA } \\
\text { FERTILIZERS }\end{array}$ & $\mathrm{kg} \mathrm{N} / \mathrm{ha}$ & $\begin{array}{l}\text { AGeNDA } \\
\text { database }\end{array}$ & 0 & 105 & 210 & 315 & $\begin{array}{l}\text { Average fertilization } \\
\text { referred to the crop } \\
\text { rotation }\end{array}$ \\
\hline MANURE & $\mathrm{kg} \mathrm{N} / \mathrm{ha}$ & $\begin{array}{l}\text { AGeNDA } \\
\text { database }\end{array}$ & 0 & 60 & 120 & 180 & $\begin{array}{l}\text { Average fertilization } \\
\text { referred to the crop } \\
\text { rotation }\end{array}$ \\
\hline WATER INPUT & $\mathrm{mm}$ & $\begin{array}{l}\text { Summ of rainfall } \\
\text { and irrigation inputs }\end{array}$ & 690 & 900 & 1200 & 1700 & \\
\hline $\begin{array}{l}\text { SOIL } \\
\text { PERMEABILITY }\end{array}$ & $\begin{array}{l}\text { Soilhydrologic } \\
\text { groups }\end{array}$ & NRCS, 1996 & A & & & $\mathrm{C} \& \mathrm{D}$ & $\begin{array}{l}\text { VLW soil map } \\
\text { (ARPAV, 2004) }\end{array}$ \\
\hline $\begin{array}{l}\text { FIELD } \\
\text { FERTILIZATION }\end{array}$ & $\mathrm{kg} \mathrm{N} / \mathrm{ha}$ & $\begin{array}{l}\text { Summ of manurel } \\
\text { and mineral fertilizers }\end{array}$ & 0 & 200 & 350 & 500 & \\
\hline RUNOFF (mm) & $\mathrm{mm}$ & SURQ, LATQ & 18 & 200 & 300 & $>300$ & \\
\hline LEACHING (mm) & $\mathrm{mm}$ & PERC & 0 & 250 & 360 & $>360$ & \\
\hline $\begin{array}{l}\text { N LOAD INTO } \\
\text { RUNOFF }\end{array}$ & $\mathrm{kg} \mathrm{N} / \mathrm{ha}$ & $\begin{array}{l}\text { NSURQ, } \\
\text { NLATQ }\end{array}$ & 0 & 3 & 6 & $>6$ & \\
\hline $\begin{array}{l}\text { N LOAD INTO } \\
\text { LEACHING }\end{array}$ & $\mathrm{kg} \mathrm{N} / \mathrm{ha}$ & NO3L & 0 & 2 & 4 & $>4$ & $\begin{array}{l}\text { SWAT output } \\
\text { parameters }\end{array}$ \\
\hline $\begin{array}{l}\text { N LOAD IN } \\
\text { SURFACE } \\
\text { WATERS } \\
\end{array}$ & $\mathrm{kg} \mathrm{N} / \mathrm{ha}$ & $\begin{array}{l}\text { ORGN_OUT; } \\
\text { NO3_OUT; } \\
\text { NH4_OUT }\end{array}$ & 4 & 10 & 22 & $>22$ & \\
\hline Note & Land use & \multicolumn{6}{|c|}{ Three typical example of crop rotation (4 years each) } \\
\hline $\begin{array}{l}\text { Tipical crop } \\
\text { Rotation }\end{array}$ & $\begin{array}{l}\text { Extensive } \\
\text { Traditional } \\
\text { Intensive }\end{array}$ & $\begin{array}{l}\text { Hay with manure } \\
\text { maize - soybean } \\
\text { maize with manure }\end{array}$ & \multicolumn{3}{|c|}{$\begin{array}{l}3 \text { years of alfa-alfa - } \\
\text { winter wheat } \\
\text { soybean - maize - } \\
\text { winter wheat - maize } \\
\text { maize - soybean } \\
\text { with manure }\end{array}$} & \multicolumn{2}{|c|}{$\begin{array}{l}\text { winter wheat - sugar } \\
\text { beat - soybean - maize } \\
\text { maize }\end{array}$} \\
\hline
\end{tabular}


Table 2. Example of experts' judgments aggregation.

\begin{tabular}{lrcc}
\hline & Low & Medium & High \\
\hline Expert 1 & $10 \%$ & $20 \%$ & $70 \%$ \\
Expert 2 & $15 \%$ & $15 \%$ & $70 \%$ \\
Expert 3 & $5 \%$ & $15 \%$ & $80 \%$ \\
Average & $10 \%$ & $17 \%$ & $73 \%$ \\
\hline
\end{tabular}

tribution across the different categories, as shown in Table 2.

The equal weighted average was applied because weighting experts' judgements was considered not feasible with robust scientific methods, nor 'politically correct' and could lead to conflicts with the experts, or reduce the transparency in decision-making processes or in the public participation approach in general.

\section{Results}

The first result obtained by the work described above was the functional BN model for the VLW case study presented in Figure 3.

This is the model structure presented to the experts and then validated. Subsequently, through the questionnaire, the experts fulfilled the CPTs tables of each node. As previously stated, in order to determine whether the aggregation could lead to different results, uncertainty analysis was carried out. The two kind of uncertainty analysis performed (group and global uncertainty) demonstrated that no meaningful effect on the target variable is determined by the selection of different input probability distribution to fill the $\mathrm{BN}$ model (see Figure 4 for an example on group uncertainty analysis).

The histograms indicate the average probability of the three levels of the target node ( $\mathrm{N}$ load in surface waters) and the error bars the maximum and minimum level that they could attain by inserting in the CPTs of each variable the different experts' judgments elicited from the experts.

According to the results of the uncertainty analysis, average experts' judgments were used as prior probabilities for the BN model.

Preliminary results obtained with the $\mathrm{BN}$ model seem to contradict the VLW policy assumptions, in terms of environmental objectives of the proposed measures. These results were indeed ambitious: less than $10 \mathrm{~kg} \mathrm{~N} \mathrm{ha}^{-1}$ of nitrogen load from agricultural sources in surface waters reaching the Venice Lagoon. This level

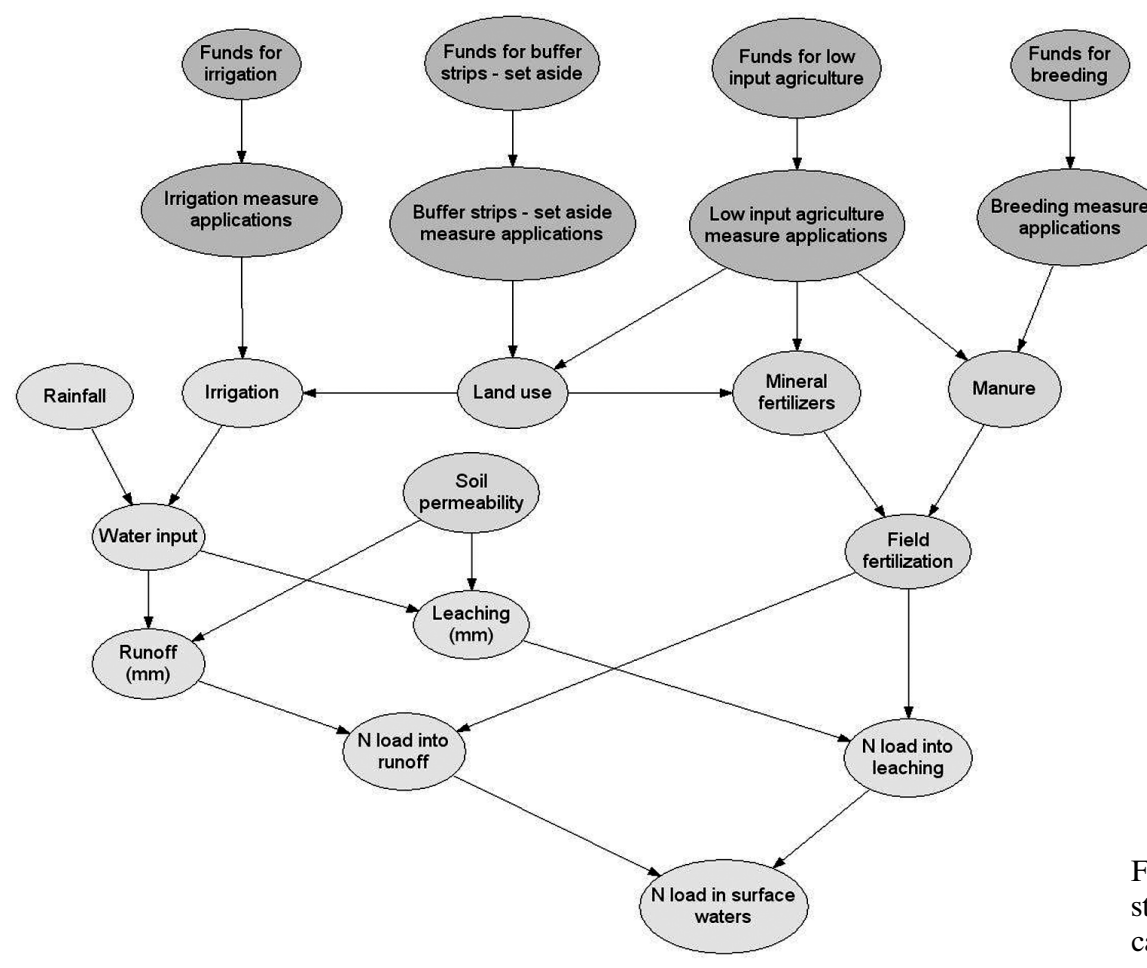

Figure 3. Bayesian Network structure obtained for the VLW case study. 
Group uncertainty analysis

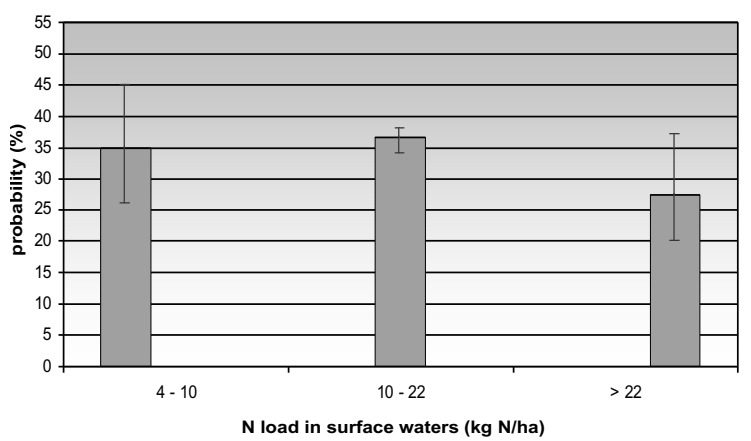

Figure 4. Group uncertainty analysis results.

considers the agricultural contribution as being approximately $50 \%$ of the total $3000 \mathrm{Mg} \mathrm{N} \mathrm{y}^{-1}$ that is the target value of the total $\mathrm{N}$ load in the lagoon.

Results obtained with experts' judgements (see Tab. 3 - Prior BN) show that agri-environmental measures have limited expected effects to achieve policy objectives: $66 \%$ probability to obtain levels of $\mathrm{N}$ loads higher than the target.

Moreover, conditional probabilities updated with the preliminary outputs of a mechanistic modelling (not described here for brevity), provide new evidences for the $\mathrm{BN}$ showing that the level of $\mathrm{N}$ load in surface waters may be even higher, and beyond $22 \mathrm{~kg} \mathrm{~N}^{-1}$ with a high probability: $63 \%$ (see Tab. 3 - Updated BN).

In terms of policy effectiveness, the results of the BN model implemented in the VLW support the hypothesis that the current mix of measures and implementation levels do not allow achieving the water quality targets in surface waters. This is, as previously stated, only a preliminary result based mainly on the expertises of a limited number of people. The obtained structure of the $\mathrm{BN}$ in itself, indeed, contributes to carefully consider the effective potential of the measures for the stated objectives, by evidencing the fact that several layers of variables lay between the application of the measures and

Table 3. The average probabilities of the nitrogen load in surface waters (target variable): prior and updated $\mathrm{BN}$.

\begin{tabular}{lcc}
\hline Ranges $\left(\mathrm{kg} \mathrm{N} \mathrm{ha}^{-1}\right)$ & Prior BN & Updated BN \\
\hline From 4 to 10 & $34 \%$ & $12 \%$ \\
From 10 to 22 & $38 \%$ & $25 \%$ \\
More then 22 & $28 \%$ & $63 \%$ \\
\hline
\end{tabular}

the target variable. In other words, a first result of the work lays in the design of the structure of the system through the BN model, that highlight how far is the target compartment (the nitrogen load in surface waters) from the compartment affected by the measures (the cultivated fields of the watershed).

Moreover, model runs show that results are not influenced in varying probabilities distribution into the administrative variables of the model (i.e. the first two layers of variables), because probability propagation does not reach the target variable (i.e. nitrogen load in surface waters).

It is important to highlight that these are preliminary results, which should be later consolidated with quantitative evidences coming from ongoing research projects, thus supporting the competent administration towards careful considerations on measures objectives and obtained results. For instance the opportunity of a cost-benefit or cost-effectiveness analysis of alternative measures, should be considered by exploring in particular the existence of minimum thresholds in the number of applications (or area affected) in order to have tangible results for the stated objectives of the policy.

\section{Discussion}

BNs have a range of advantages for investigating complex environmental problems and their management as presented in various works (such as Bromely et al., 2005; Dorner et al., 2007; Handerson and Burn, 2004; Martin de Santa Olalla et al., 2005 and 2007). BNs allow the combination of information that differ for qualities and sources (rough data, model outputs and experts' judgements), and the use of conditional probabilities that implicitly incorporates uncertainty. Furthermore BNs increase their flexibility in management frameworks when combined with cognitive maps, becoming a powerful tool for supporting decision-makers in participatory contexts characterised by incomplete knowledge. Moreover, BNs such as the proposed framework allow the analysis of the effects of different management interventions also within the context of alternative scenarios.

The new methodological framework described above resulted as being a promising tool 
in particular to manage different sources of data within the same probabilistic modelling framework, to conduct a scenario analysis, and to handle situation with lack of information and uncertainty. BNs confirmed also their potentials for supporting integrated - economic, environmental and social - assessment.

Regarding specifically the policy assessment of agri-environmental measures for the VLW it is important to highlight once more that the results obtained are the outputs of a preliminary methodological test, therefore, they should be considered as exploratory and not yet ready for supporting revisions of current measures or future policy suggestions.

Further investigations are currently in progress regarding the limited probability propagation, which could be due to the high numbers of variables interposed between the administrative nodes and the target, and/or to the CPTs of interposed variables that limit the effects of changes in parent nodes. Both problems show interesting relations with the assessment issue and stimulate discussions about the effectiveness of the measures.

The BN model briefly presented herein shows also potential for future re-use. The model, updated with the evidences emerging from ongoing monitoring and modelling efforts, will indeed allow not only ex-post assessment of policy measures, like this case, but also ex-ante evaluations and, very importantly, with associated documentation of outputs uncertainty.

\section{References}

ARPAV (Agenzia Regionale per la Protezione dell'Ambiente), 2004. Carta dei suoli del bacino scolante in laguna di Venezia. A cura del Servizio Osservatorio Suolo e Rifiuti di Castelfranco Veneto - Dipartimento Provinciale di Treviso, ISBN 88-7504-81-8.

Borsuk M.E., Craig A.E., Reckhow K.H. 2004. A Bayesian network of eutrophication models for synthesis, prediction, and uncertainty analysis. Ecological Modelling, 173:219-239.

Bromley J., Jackson N.A., Clymer O.J., Giacomello A.M., Jensen F.V. 2005. The use of Hugin ${ }^{\circledR}$ to develop Bayesian networks as an aid to integrated water resource planning. Environmental Modelling \& Software, 20, 2:231-242.

Cain J. 2001. Planning improvements in natural resources management - Guidelines for using Bayesian networks to support the planning and management of development programmes in the water sector and beyond, British Library.

Clemen R.T., Reilly T. 2001. Making Hard Decisions with Decision Tools. Duxbury Thomson Learning, Pacific Grove, CA.

Clemen R.T., Winkler R.L. 1999. Combining probability distributions from experts in risk analysis. Risk Analysis, 19:187-203.

Dorner S., Shi J., Swayne D. 2007. Multi-objective modelling and decision support using a Bayesian network approximation to a non-point source pollution model. Environmental Modelling \& Software, 22, 2:211-222.

EEA European Environmental Agency 1999. Environmental indicators: Typology and Overview. EEA Technical Report n. 25. European Environmental Agency, Copehagen.

Giupponi C. 2002. AGeNDA: a project for developing a new tool for sustainable farm management. In: K.J. Poppe, A. Povellato (eds.): European farmers and the growing of data, INEA, 43-53.

Giupponi C., Fassio A., Sgobbi A. 2008. Evaluation of Agri-Environmental Measures in the Venice Lagoon Watershed. Expert Knowledge Elicitation and Multi-Criteria Analysis. Italian Journal of Agronomy, 3:147-165.

Henderson J.S., Burn R.W. 2004. Uptake pathways: the potential of Bayesian belief networks to assist the management, monitoring and evaluation of development-orientated research. Agricultural Systems, 79, 1:3-15.

Lasut A. 2005. Creative Thinking and Modelling for the Decision Support in Water Management. Working paper FEEM n. 81.

Leonard R.A., Knisel W.G., Still D.A. 1987. GLEAMS: Groundwater Loading Effects of Agricultural Management Systems. Trans., American Society of Agricultural Engeneers, 30:1403-1418.

Martin de Santa Olalla F., Dominguez A., Ortega F., Artiago A., Faberio C. 2007. Bayesian networks in planning a large aquifer in Eastern Mancha, Spain. Environmental Modelling \& Software, 22, 8:1089-1100.

Martin de Santa Olalla F.J., Dominguez A., Artiago A., Faberio C., Ortega J.F. 2005. Integrated water resources management of the Hydrogeological Unit "Eastern Mancha" using Bayesian Belief Networks. Agricultural Water Management, 77, 1-3:21-36.

Meyer M.M., Booker J. 1991. Eliciting and analyzing expert judgement: a practical guide. St Edmundsbury Press Limited, Bury St Edmunds, Suffolk, ISBN 0-12493230-4.

Morgan M.G., Henrion M. 1990. Uncertainty. In: A guide to dealing with uncertainty in quantitative risk and policy analysis. Cambridge University Press, ISBN 0521-36542-2.

Korb K.B., Nicholson A.E. 2004. Bayesian Artificial Intelligence. Chapman \& Hall/CRC Press, UK, ISBN 158488-387-1. 
Ripa M.N., Leone A., Garnier M., Lo Porto A. 2006. Agricultural land use and best management practices to control nonpoint water pollution. Environmental Management, 38:253-266.

Nadkarni S., Shenoy P.P. 2004. A causal mapping approach to constructing Bayesian networks, Decision Support Systems, 38:259-281.
NRCS (Natural Resource Conservation Service), 1996. National soil survey handbook, title 430-VI. U.S. Government Printing Office, Washington, D.C.

O'Hagan A., Caitlin E., Buck C.E., Daneshkhah A., Eiser J.R., Garthwaite P.H., Jenkinson D.J., Oakley J.E., Rakow T. 2006. Uncertainty judgements: Eliciting Experts' Probabilities. Jhon Wiley \& Sons, Ltd, ISBN 0-470-02999-4. 